\title{
Receptor-Type Tyrosine-Protein Phosphatase Gamma
}

National Cancer Institute

\section{Source}

National Cancer Institute. Receptor-Type Tyrosine-Protein Phosphatase Gamma. NCI Thesaurus. Code C37311.

Receptor-type tyrosine-protein phosphatase gamma (1445 aa, 162 kDa) is encoded by the human PTPRG gene. This protein is involved in both protein dephosphorylation and signal transduction. 